\title{
Silencing ephrinB3 improves functional recovery following spinal cord injury
}

\author{
YANG QU, JIANWU ZHAO, YANG WANG and ZHONGLI GAO \\ Department of Orthopaedics, China-Japan Union Hospital of Jilin University, Changchun, Jilin 13033, P.R. China
}

Received September 23, 2013; Accepted February 25, 2014

DOI: $10.3892 / \mathrm{mmr} .2014 .2019$

\begin{abstract}
EphrinB3 may restrict axonal regeneration and recovery following traumatic injury of the adult mammalian central nervous system (CNS). Therefore, inhibition of ephrinB3 expression may enhance the ability of the nervous system to regenerate following damage. In the present study, lentiviral expressing vectors, pGCSIL-GFP, expressing an active small interfering RNA (siRNA) targeting the EphB3 sequence, were used to determine the effect of inhibiting EphB3 on nerve functional recovery and regeneration. Basso-BeattieBresnahan (BBB) locomotor scores and growth-associated protein, $43 \mathrm{kDa}$ (GAP43) expression levels were determined at 1,2, 4 and 8 weeks following transplantation of the siRNA. It was identified that EphB3 mRNA and protein levels in the siRNA group were significantly reduced $(\mathrm{P}<0.01)$ in the spine compared with the control group, at four weeks following intraparenchymal administration of the siRNA into the right lumbar. BBB locomotor scores were significantly increased $(\mathrm{P}<0.05)$ in siRNA animals compared with the sham group, at 1,2, 4 and 8 weeks following transplantation of the siRNA. In addition, a significant increase in GAP43 expression was detected in the siRNA group compared with the control group. This preclinical study demonstrates that ephrinB3 silencing contributes to axonal growth regeneration and improves recovery from spinal cord injury (SCI).
\end{abstract}

\section{Introduction}

Spinal cord injury (SCI) is a major clinical problem worldwide, due to the prevalence of permanent neurological deficits and secondary complications (1). It is characterized by a total or partial loss of motor and sensory functions due to an inability of neurons to regenerate. Axon regeneration is restricted by cell-autonomous factors $(2,3)$, by the astroglial scar $(4,5)$ and

Correspondence to: Professor Zhongli Gao, Department of Orthopaedics, China-Japan Union Hospital of Jilin University, No. 126 Xian Tai Street, Changchun, Jilin 13033, P.R. China E-mail: gaozhongli518@126.com

Key words: spinal cord injury, ephrinB3, axonal regeneration, RNA interference by central nervous system (CNS) myelin $(5,6)$. An inhibitory growth environment for axons has been attributed to products of glial cells, including oligodendrocytes and astrocytes. Myelin-derived inhibitory proteins include myelin-associated glycoprotein $(7,8)$ (MAG), Nogo-A $(9,10)$, oligodendrocyteassociated glycoprotein (OMgp), repulsive guidance molecule (RGM) (11), semaphorins (12), netrins (13) and ephrin/eph (14). However, previous studies have demonstrated that NOGO, MAG and OMgp may have a tenuous role in neural regeneration following SCI (5). Therefore, elucidating the molecular role of the Eph receptor in SCI may facilitate the development of novel treatment strategies to improve clinical outcomes for the disease.

Eph receptor tyrosine kinases and their membraneanchored ligands, known as ephrins, constitute the largest receptor tyrosine kinase (RTK) subfamily, including at least 16 receptors and 9 ligands in vertebrates $(15,16)$. The Ephs and ephrins are divided into A/B classes based on their binding affinities. In general, EphA receptors bind ephrin-A molecules whereas the EphB receptors bind ephrin-B molecules. Eph receptors have diverse activities, including widespread effects on intercellular junctions, cell shape, cell-substrate adhesion, cell movement and angiogenesis. In addition, several recent studies have demonstrated that Eph/ephrin signaling has a known role in the regulation of axon guidance through contact repulsion, inducing neuronal growth cone collapse during the formation of sensory maps in the developing brain $(16,17)$.

Of these molecules, ephrinB3 is known to be expressed by myelinating oligodendrocytes and to inhibit axonal extension (18). Macrophage EphB3 has also been implicated in adult axon regeneration (19). Furthermore, ephrinB3 has been documented to function as a midline repellent for axons of the corticospinal tract in the spinal cord $(17,20,21)$. Additionally, Asante et al demonstrated that ephrinB3 is required for axonal growth inhibition by detergent-resistant fractions of CNS myelin in vitro (18). Duffy et al (22) also identified that ephrinB3 contributes to myelin-derived axonal growth inhibition and limits recovery from adult CNS trauma. These data suggest that ephrinB3 contributes to myelin-dependent failure of axonal regeneration. Thus, inhibition of ephrinB3 expression may contribute to myelin-dependent failure of axonal regeneration following SCI.

The present study aimed to investigate the effects of intraparenchymal administration of recombinant lentiviral expressing vectors, expressing an active EphB3 siRNA sequence, into the 
spinal cord of adult rats, on the locomotion function recovery and axonal regeneration following SCI.

\section{Materials and methods}

siRNA design and conduct. Two different siRNAs encoding ephrinB3 were designed as described previously by Elbashir et al (23). Sequences of the siRNAs used in the present study are as followed: siRNA1: cggcaGAGGGTGGTTACGTGCTTTCTCGAGAAAGCACGTAACCACCCT CtgTTTTTg; siRNA2: CcgggaTCCCACCACGA TTACTACACTCGAGTGTAGTAATCGTGGTGGGAtcTTT TTg. An additional scrambled sequence was also designed as a negative control (NC) and the sequences were as follows: CcggTTCTCCGAACGTGTCACGTTTCAAGAGAACGTG ACACGTTCGGAGAATTTTTg. Replication deficient, selfinactivating lentiviral expressing vectors PGCSIL-RNAi-GFP (Shanghai Gene Kaiji, Shanghai, China) were generated as follows: In brief, the cDNAs corresponding to the two siRNAs and NC were subcloned into the lentiviral expression vector pGCSIL-RNAi-GFP (Shanghai Gene Chem, Shanghai, China). The resulting recombinant lentiviral vectors were designated as LV-siRNA 1, LV-siRNA 2 and LV-NC. To produce the lentivirus, the $293 \mathrm{~T}$ cells were transfected with $20 \mu \mathrm{g}$ of LV-siRNA 1, LV-siRNA 2 and LV-NC plasmid, together with $15 \mu \mathrm{g}$ of pHelper1.0 and $10 \mu \mathrm{g}$ of pHelper 2.0 packaging plasmids, respectively (24). The culture medium was collected $48 \mathrm{~h}$ following transfection, then concentrated by ultracentrifugation, aliquoted and stored at $-80^{\circ} \mathrm{C}$ until use. The titer of lentivirus was determined by hole-by-dilution titer assay (25). Four days following a single exposure of 293T cells to the lentivirus, strong green fluorescence was demonstrated in $>90 \%$ of cells, indicating a high and stable transduction of the lentiviral vector system. The final titer of pFU-shRNA1, pFU-shRNA-2 and pFU-NC were $4 \times 10^{8} \mathrm{TU} / \mathrm{ml}, 5 \times 10^{8} \mathrm{TU} / \mathrm{ml}$, $4 \times 10^{8} \mathrm{TU} / \mathrm{ml}$ and $1 \times 10^{9} \mathrm{TU} / \mathrm{ml}$, respectively.

Animals. In the present study, 50 adult female Wistar rats (weighing, 250-300 g) were purchased from the Center for Experimental Animals of Jilin University (Changchun, China) and were housed at $24 \pm 1^{\circ} \mathrm{C}$ on a $12 \mathrm{~h}$ light-dark cycle and allowed free access to laboratory chow and water. All animal experiments were conducted in accordance with the National Institute of Health Guide for the Care and Use of Laboratory Animals. All animal studies were approved by the Animal Care and Use Committee at the Jilin University (Changchun, China) and were in accordance with the University's guidelines for the care and use of laboratory animals. The study was approved by the Ethics Committee of Jilin University.

SCI and virus injection. The animals were anesthetized using intraperitoneal ketamine $(80 \mathrm{mg} / \mathrm{kg})$, xylazine $(10 \mathrm{mg} / \mathrm{kg})$ and $0.9 \mathrm{mg} / \mathrm{kg}$ acepromazine. Rats were placed prone on an operating table covered with a warming blanket. A dorsal incision was made to expose T10 vertebra and a laminectomy was performed, leaving the spinal segment exposed. Following exposure of the T10 segment by laminectomy, animals received a moderate contusion using the NYU impactor that provides a contusion of $12.5 \mathrm{~g} / \mathrm{cm}$ as previously described (14)
Sprague Dawley rats with SCI were randomly divided into a LV-siRNA 1, LV-siRNA 2, LV-NC and PBS group ( $\mathrm{n}=10 /$ group), virus ( 5 or $10 \mu \mathrm{l}$ ) was administered three days following SCI, which was flushed using 10 or $5 \mu \mathrm{l}$ of PBS. The rats in each of the PBS, LV-NC, LV-siRNA 1 and LV-siRNA 2 groups were intrathecally delivered with PBS, LV-NC or LV-siRNA1, LV-siRNA2 plus PBS in a total volume of $15 \mu \mathrm{l}$, respectively. The L10-11 lumbar segment of the spinal cord was removed four weeks following administration. The protein and mRNA expression of EphB3 receptor A in the spinal cord was measured by western blot analysis and quantitative PCR (qPCR), respectively.

$q P C R$. Total RNA was isolated from frozen spinal tissue using TRIzol reagent (Invitrogen Life Technologies, Carlsbad, CA, USA) according to the manufacturer's instructions. Using mRNA as a template, single-stranded cDNAs were generated by Superscript II reverse transcriptase (Invitrogen Life Technologies) according to the manufacturer's instructions. The amplification mixture $(20 \mu \mathrm{l})$ contained $4 \mu \mathrm{l}$ of cDNA, $5 \mu \mathrm{l}$ of primers and $11 \mu \mathrm{l}$ of Ex Taq SYBER Premix (Takara Bio, Inc., Shiga, Japan). The amplification was performed at $95^{\circ} \mathrm{C}$ for $2 \mathrm{~min}$, followed by 40 cycles of $95^{\circ} \mathrm{C}$ for $30 \mathrm{sec}$ and $60^{\circ} \mathrm{C}$ for $1 \mathrm{~min}$. All qPCR were performed in triplicate to ensure quantitative accuracy. PCR was performed on the ABI 7500HT instrument and data were analyzed based on the $2^{-\Delta \Delta \mathrm{CT}}$ method with normalization software. Primers utilized for the qPCR were as follows: EphB3: sense, 5'-ACTCAGCCTGGAGCCTGTCTAC-3'; anti-sense, 5'-CGATCTGAGGGTAAAGCACGTA-3'. GAPDH: sense, 5'-TGGAGAAACCTGCCAAGTATGA-3' and anti-sense, 5'-TGGAAGAATGGGAGTTGCTGT-3'. The expression of interest genes was determined by normalization of the threshold cycle $(\mathrm{Ct})$ of these genes to that of the control GAPDH.

Western blot analysis. Lumbar spinal enlargements (L10-11) were removed and homogenized in SDS sample buffer containing a protease inhibitor cocktail (Sigma, St. Louis, MO, USA). Protein samples were separated on an $8 \%$ SDS-polyacrylamide gel and transferred onto nitrocellulose membranes (Santa Cruz Biotechnology, Inc., Santa Cruz, CA, USA). Following blockade in TBS containing 5\% skimmed milk and $0.1 \%$ Tween-20 for $2 \mathrm{~h}$ at room temperature, they were then processed for immunostaining with either an antiserum against a monoclonal antibody against rat $\beta$-actin (1:5,000; Sigma), a polyclonal custom-made antibody against GAP43 (1:1,000; Invitrogen Life Technologies) or a polyclonal antibody against rat ephrinB3 (1:5,000; Serotec, Oxford, UK) at $4^{\circ} \mathrm{C}$ overnight. The bound antibodies were visualized with anti-rabbit, anti-mouse immunoglobulin $\mathrm{G}(\operatorname{IgG} ; 1: 10,000)$ or anti-sheep $(1: 10,000)$ secondary antibodies conjugated with horseradish peroxidase (Sigma) following incubation for $2 \mathrm{~h}$ at room temperature. The antigen-antibody complexes were detected by ECL (Amersham Biosciences, Pittsburgh, PA, USA) according to the manufacturer's instructions.

Behavioral assessment (locomotor function). Locomotor activity was evaluated over a period of $5 \mathrm{~min}$ by an open-field walking test. One animal at a time was allowed to move freely 
inside a circular plastic tray $(90 \mathrm{~cm}$ diameter x $24 \mathrm{~cm}$ wall height).

Two independent examiners observed the hind limb movements of the rat and scored the locomotor function according to the Basso-Beattie-Bresnahan (BBB) scale (26) that ranges from 0 (paralysis) to 21 points (normal gait). The final score for each animal was the mean value of the two examiners. During the open field activity, the animals were also video monitored with a digital camera. Functional tests were performed prior to the injury and transplantation, and weekly for eight weeks following siRNA transplantation.

Walking-beam test. The motor function of the hindlimbs was also examined utilizing the walking-beam test. The apparatus consisted of a $3.4 \mathrm{~cm}$-wide and $140 \mathrm{~cm}$-long wooden rectangular beam. A goal box was placed at one end. The central $1 \mathrm{~m}$ of the beam was used to evaluate the walking distance. The latency and trajectory to traverse the beam were recorded with a video-tracking system for a maximum of $1 \mathrm{~min}$. Following pretraining, two trials were conducted each day for three consecutive days. The animals were examined prior to the surgery and every week from the second week following the injection of LV-siRNA1, LV-siRNA2, LV-NC or PBS. A 0 to 7-point scale modified from Goldstein (27) was used to evaluate the locomotor function.

Immunohistochemical analysis. To analyze the volume of the spared white and gray matter, and the extent of axonal sprouting, animals with SCI $(n=7)$ were sacrificed four weeks following siRNA-ephrinB3 transplantation. For perfusion, the animals were deeply anesthetized with ketamine $(100 \mathrm{mg} / \mathrm{kg})$ and xylazine $(20 \mathrm{mg} / \mathrm{kg})$. Their chests were opened and transcardial perfusion was washed with PBS until the liver tissue was clean, followed by perfusion with a $4 \%$ paraformaldehyde (PFA) solution in PBS. A $2 \mathrm{~cm}$ long segment of the spinal cord was dissected between $1 \mathrm{~cm}$ cranial and $1 \mathrm{~cm}$ caudal to the injury epicenter. Serial cross sections, $5 \mu \mathrm{m}$ thick, were incised using a K400 microtome (MICROM International $\mathrm{GmbH}$, Walldorf, Germany) following paraffin embedding. Sections were also dewaxed in xylene, rehydrated in descending alcohols and blocked for endogenous peroxidase and avidin/biotin activities. Following blocking with $3 \%$ BSA in 0.01 M PBS (pH 7.2), the sections were incubated with mouse monoclonal antibody against GAP43 (Santa Cruz Biotechnology, Inc.) at a dilution of 1:1,000 overnight at $4^{\circ} \mathrm{C}$. Then, it was washed in $0.01 \mathrm{M}$ PBS ( $\mathrm{pH}$ 7.2) for $5 \mathrm{~min}$. The sections were then incubated with biotin-labeled rabbit anti-mouse antibody (1:100; ZSGB-BIO, Beijing, China) for $2 \mathrm{~h}$. Following washing with PBS three times, immunostaining was visualized using a streptavidin-peroxidase reaction system and then developed with diaminobenzidine (DAB)- $\mathrm{H}_{2} \mathrm{O}_{2}$ (Wuhan Boster Biological Technology, Ltd., Wuhan, China). High-magnification images of transverse sections, separated by a $1 \mathrm{~mm}$ distance in all of the animal groups stained for GAP43, were obtained and GAP43-positive fibers were manually counted.

Statistical analysis. All data are expressed as the mean \pm SEM. Statistical analysis between two samples was performed using Student's t-test. Statistical comparison of more than two groups was performed using one-way ANOVA followed by a Tukey post hoc test. The significance of any differences in behavioral data of different experimental groups was assessed using two-way ANOVA. $\mathrm{P}<0.05$ was considered to indicate a statistically significant difference.

\section{Results}

Downregulation of ephrinB3 expression by silencing ephrinB3. qPCR was performed 28 days following injection to evaluate the level of EphB3 mRNA expression. The results demonstrated there was no significant inhibition of EphB3 mRNA expression in the LV-NC group, and there were no significant differences between the LV-NC group and control group (PBS group). By contrast, ephrinB3 expression in the siRNA group was significantly decreased compared with the LV group and control group (PBS group) following injection. The effect of siRNA treatment on ephrinB3 protein expression was assessed by western blot analysis. As revealed in Fig. 1, there was no significant inhibition of EphB3 protein expression in the LV-NC group ( $\mathrm{P}>0.05)$, while the band density decreased markedly in the LV-siRNA-1, LV-siRNA-2 as compared with the LV-NC $(\mathrm{P}<0.01)$ group. These results demonstrated that siRNA targeting ephrinB3 significantly reduced ephrinB3 protein expression levels in rats in vivo $(\mathrm{P}<0.01)$.

Effects of silencing ephrinB3 on hindlimb recovery during $S C I$. The BBB locomotor grading scale was used to assess the effects of EphB3-siRNA on the locomotive behavior of injured rats. The two-way ANOVA followed by Bonferroni post hoc analysis demonstrated highly significant differences in locomotor behavior between LV-siRNA-1, LV-siRNA-2 and the LV-NC groups ( $\mathrm{P}<0.01$; Fig. 2). The data transformation and analysis revealed improved BBB scores in the LV-siRNA-1 and LV-siRNA-2 compared with the LV-NC group $(\mathrm{P}<0.01)$ (Fig. 2), which revealed that knockout ephrinB3 may increase $\mathrm{BBB}$ scores to a certain extent.

Effects of silencing ephrinB3 on hindlimb motor function following SCI. The ability to traverse a beam with a flat surface was examined weekly. Rats with SCI, injected with PBS, were not able to transverse the beam at all, as no signs of weight support and/or stepping were observed. However, following siRNA ephrinB3 treatment, the rats began to maintain their body weight on the beam for $60 \mathrm{sec}$ and a number of them were able to traverse the full length of the beam. A statistically significant difference appeared at seven weeks following SCI between the scores of the control and siRNA groups $(\mathrm{P}<0.01)$. In addition, no significant difference was noted between the LV-NC and control (PBS) groups (Fig. 3).

Evaluation of axonal sprouting. Axonal sprouting in the lesion was expressed as the number of GAP43 + fibers (Fig. 4). Staining for GAP43 was more intense in the cross-sections of the spinal cord tissue of LV-siRNA1 and LV-siRNA2 groups than in the sections from control and LV-NC groups (Fig. 4A). The number of GAP43 + axonal fibers per section was significantly increased in LV-siRNA1 and LV-siRNA2 groups compared with the control group (Fig. 4B). Furthermore, the GAP43 expression was also measured by western blot analysis, and the results revealed that the GAP43 protein expression 
A

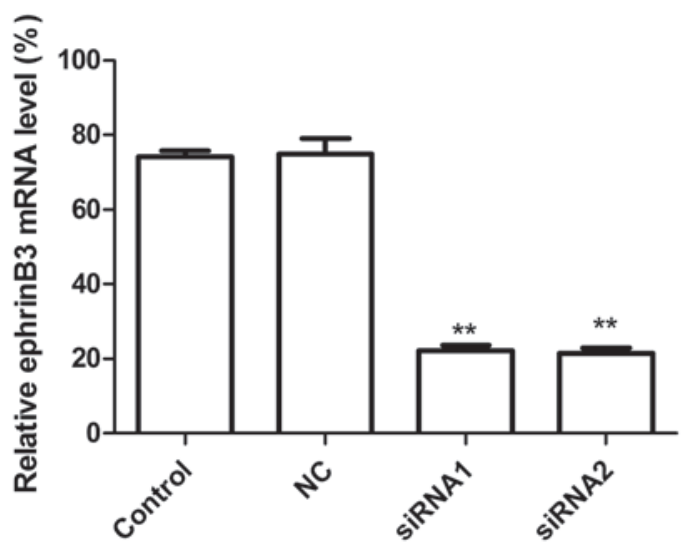

B

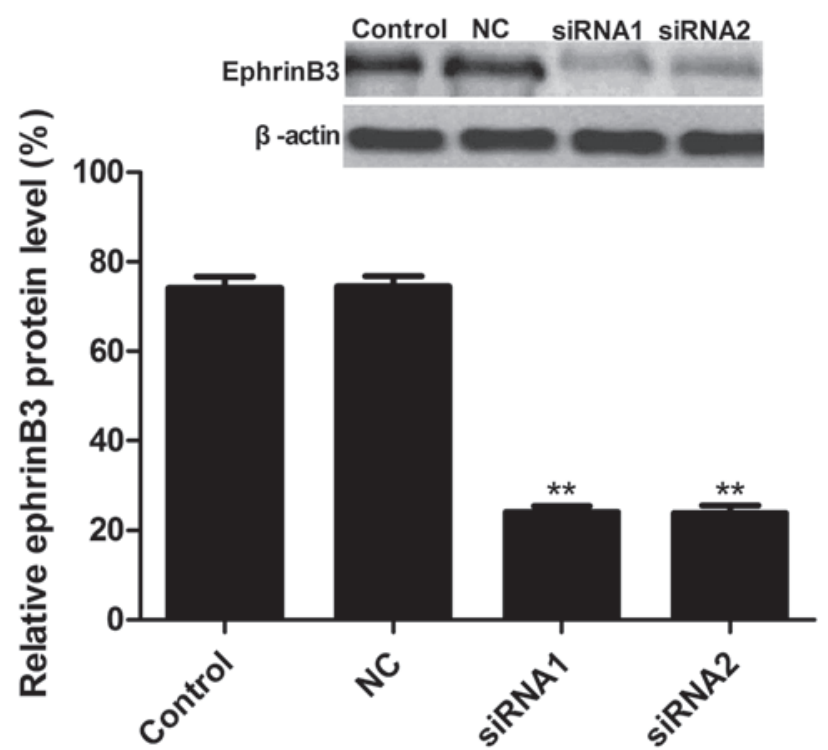

Figure 1. Silencing ephrinB3 inhibited the ephrinB3 expression in the spinal cord of rats following SCI. (A) qPCR analysis of eprinB3 mRNA expression following RNAi silencing. (B) Western blot analysis of ephrinB3 protein expression following RNAi silencing. ${ }^{* *} \mathrm{P}<0.01$ vs. the control. SCI, spinal cord injury; qPCR, quantitative PCR; siRNA, small interfering RNA; NC, negative control.

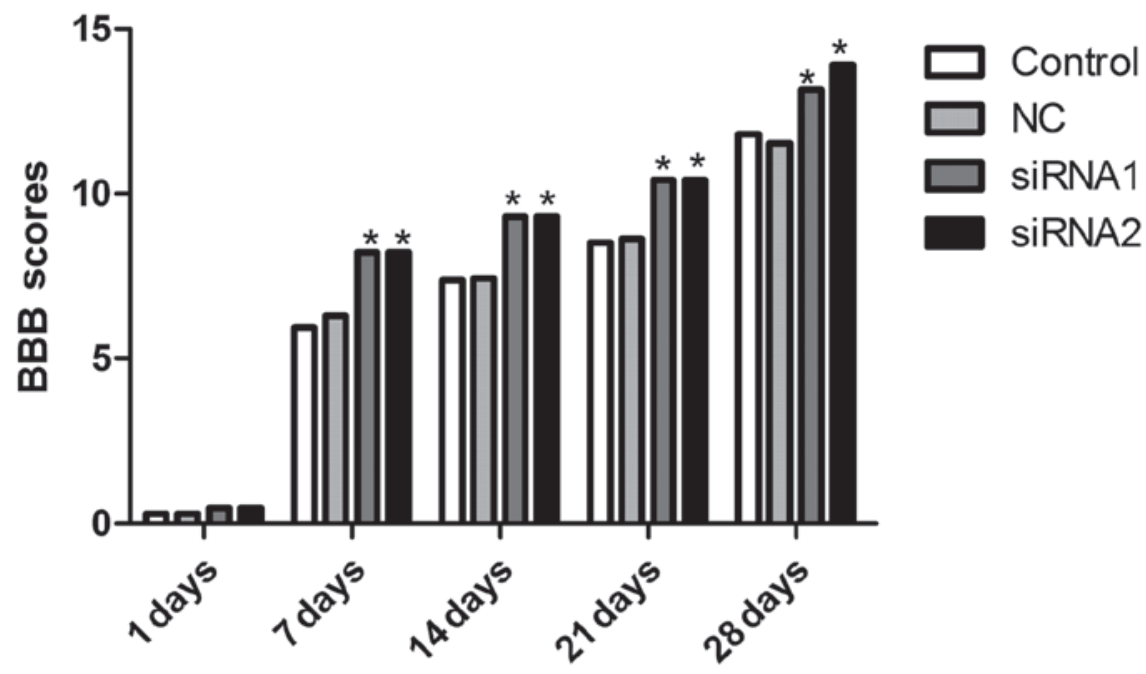

Figure 2. The BBB scores in different groups at 1, 7, 14, 21 and 28 days following injection of siRNA. ${ }^{*} \mathrm{P}<0.05$ vs. the control. BBB, Basso-Beattie-Bresnahan scale; siRNA, small interfering RNA; NC, negative control.

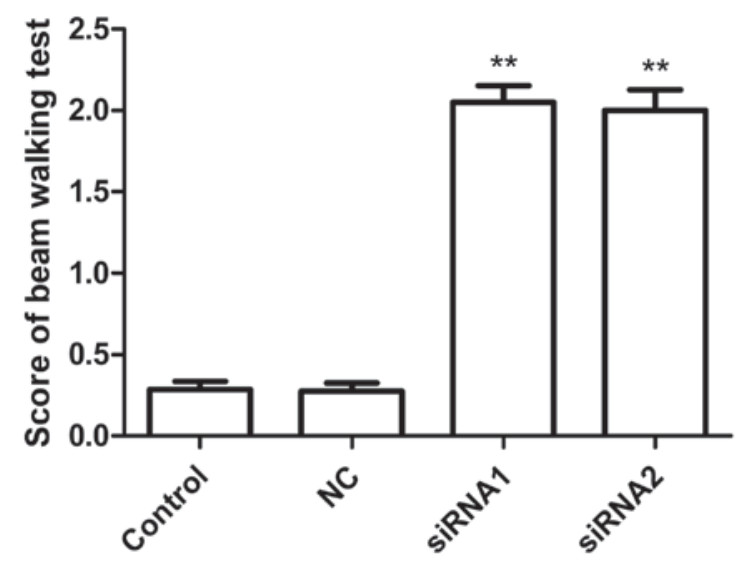

Figure 3. Scores of the beam walking test in the different groups four weeks following siRNA injection. ${ }^{* *} \mathrm{P}<0.01$ vs. the control. siRNA, small interfering RNA; NC, negative control. level was higher in the LV-siRNA1 and LV-siRNA2 groups than that of the control and LV-NC groups (Fig. 4C).

\section{Discussion}

SCI triggers the re-expression of inhibitory molecules present in the early stages of development, contributing to the prevention of axonal regeneration. Ephrins and their receptors are well known and intensively studied neurite outgrowth inhibitory molecules $(14,28)$. Previous studies have demonstrated that Eph/ephrin may also be exploited in regenerative medicine due to the roles of the Eph/ephrin system in stem cell proliferation and differentiation (29). In addition, interfering with this system in the nervous system may also be useful to treat diseases where excessive extracellular levels of the neurotransmitter glutamate causes hyperexcitability or toxicity (30). The 
A

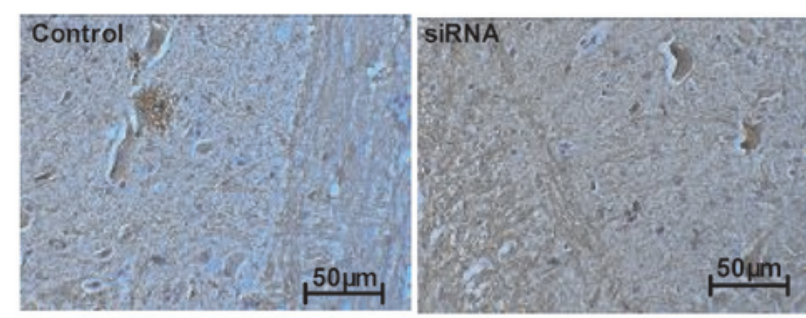

B

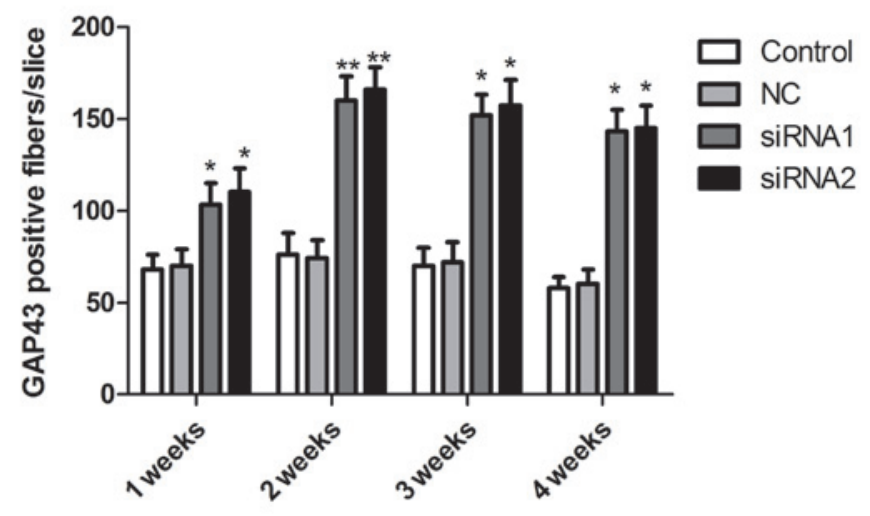

C

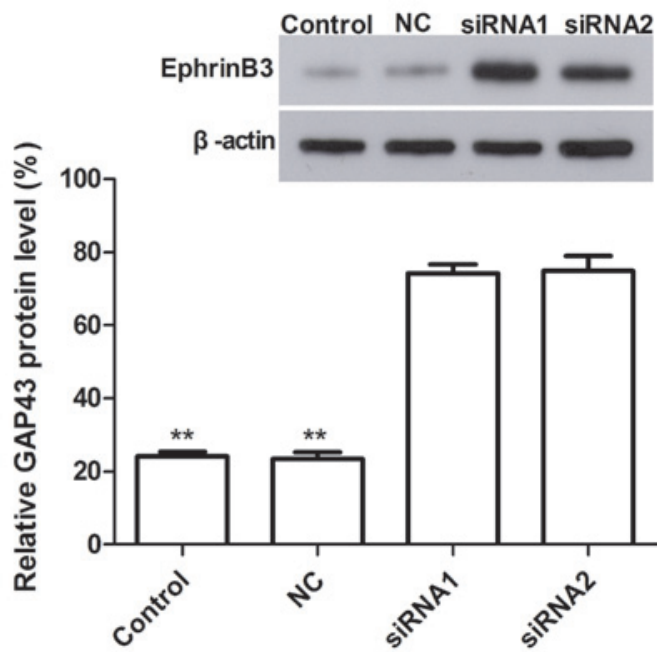

Figure 4. Axonal sprouting in the injured spinal cords of control rats and rats transplanted with siRNA. (A) Staining for GAP43 in the injured spinal cord tissue of rats transplanted with siRNA and control animals. (B) Quantitative analysis of the number of GAP43-positive fibers in the spinal cord tissue of control and siRNA injected animals at different time points. (C) GAP43 expression in the spinal cord tissue of control and siRNA injected animals four weeks following transplantation of siRNA. ${ }^{*} \mathrm{P}<0.05,{ }^{* *} \mathrm{P}<0.01$ vs. the control. GAP43, growth-associated protein, $43 \mathrm{kDa}$; siRNA, small interfering RNA; NC, negative control.

results of the present study are consistent with this evidence. It was demonstrated that the downregulation of ephrinB3 by siRNA increased the BBB scores and contributed to hindlimb recovery, which further demonstrated that Ephrin/Eph has an important role in the functional recovery of the nervous system.

Goldshmit et al revealed that the ephrin-B3-EphA4 system is active in myelin inhibition, regeneration and functional recovery following SCI using EphA4 knockout mice (31). Benson et al further demonstrated that postnatal EphA4-positive cortical neurons retain their sensitivity to the ephrin-B3 in myelin, and that this ligand accounts for a fraction of the inhibitory activity in CNS myelin preparations, equivalent to the p75-mediated activities of Nogo-66, MAG and OMgp combined (32). Furthermore, Duffy et al (22) demonstrated that ephrinB3 has a role as a myelin based inhibitory protein in CNS repair, and that it may function in parallel or synergistically with Nogo, MAG and OMgp. These studies revealed that ephrinB3 has a key role in CNS repair and functional recovery using knockout mice, which suggests that silencing ephrinB3 contributes to functional recovery following SCI. Targeted delivery of imaging agents, chemotherapeutic drugs or siRNA inhibition of the expression of high levels of ephrinB3 also offers clinical applications for novel diagnostic and therapeutic strategies for the condition. Therefore, the present study, using ephrinB3 knockout by RNA interference technology, provided further evidence that silencing ephrinB3 improves functional recovery following SCI.

Directly delivered siRNAs have demonstrated therapeutic efficacy in animal models for neuropathic pain (33), as have viral vector-delivered shRNAs for spinal cerebellar ataxia 1 (SCA1) (34), Huntington's disease (35) and amyotrophic lateral sclerosis $(36,37)$. In addition, previous studies have revealed that viral-mediated gene transfer is considered to be the most efficient system for delivering therapeutic proteins in vivo (38). Lentiviral vectors have been widely used due to their relatively limited host-inflammatory response and potential to yield sustained (in theory life-long) gene silencing (39). In the present study, lentiviral expressing vectors pGCSIL-GFP vectors expressing an active small interfering RNA (siRNA) targeting EphB3 sequence were used to determine the effect of inhibiting EphB3 on functional recovery and nervous regeneration. The data demonstrated that silencing ephrinB3 by siRNA may improve functional recovery following SCI. These data suggest lentiviral expression vectors encoding ephrinB3 may have potential clinical applications as a gene therapy approach in the treatment of SCI.

In conclusion, the data revealed that the EphB3 knockdown not only resulted in a decrease in the mRNA and protein expression in vivo, but also contributed to the increase in BBB scores and axonal regeneration. This preclinical study demonstrates the use of RNAi to target eprinB3 genes may be 
of value clinically, as a novel method in the treatment of SCI and other CNS diseases.

\section{Acknowledgements}

This study was supported by the Science and Technology Research and Innovation Team fund of Jilin Province (JL2012062).

\section{References}

1. Kose EA, Bakar B, Ayva SK, Kilinc K and Apan A: Neuroprotective effects of racemic ketamine and (S)-ketamine on spinal cord injury in rat. Injury 43: 1124-1130, 2012.

2. Bulsara KR, Iskandar BJ, Villavicencio AT and Skene JH: A new millenium for spinal cord regeneration: growth-associated genes. Spine (Phila Pa 1976) 27: 1946-1949,2002.

3. Szpara ML, Vranizan K, Tai YC, Goodman CS, Speed TP and Ngai J: Analysis of gene expression during neurite outgrowth and regeneration. BMC Neurosci 8: 100, 2007.

4. Busch SA and Silver J: The role of extracellular matrix in CNS regeneration. Curr Opin Neurobiol 17: 120-127, 2007.

5. Liu BP, Cafferty WB, Budel SO and Strittmatter SM: Extracellular regulators of axonal growth in the adult central nervous system. Philos Trans R Soc Lond B Biol Sci 361: 15931610, 2006.

6. McGee AW and Strittmatter SM: The Nogo-66 receptor: focusing myelin inhibition of axon regeneration. Trends Neurosci 26:193-198,2003.

7. McKerracher L, David S, Jackson DL, et al: David S, Jackson DL, Kottis V, Dunn RJ and Braun PE: Identification of myelinassociated glycoprotein as a major myelin-derived inhibitor of neurite growth. Neuron 13: 805-811, 1994.

8. Mukhopadhyay G, Doherty P, Walsh FS, Crocker PR and Filbin MT: A novel role for myelin-associated glycoprotein as an inhibitor of axonal regeneration. Neuron 13: 757-767, 1994.

9. Chen MS, Huber AB, van der Haar ME, Frank M, Schnell L, Spillmann AA, Christ F, Schwab ME: Nogo-A is a myelin-associated neurite outgrowth inhibitor and an antigen for monoclonal antibody IN-1. Nature 403: 434-439, 2000.

10. GrandPré T, Nakamura F, Vartanian T and Strittmatter SM: Identification of the Nogo inhibitor of axon regeneration as a Reticulon protein. Nature 403: 439-444, 2000.

11. Hata K, Hata K, Fujitani M, Yasuda Y, Doya H, Saito T, Yamagishi S, Mueller BK and Yamashita T: RGMa inhibition promotes axonal growth and recovery after spinal cord injury. J Cell Biol 173: 47-58, 2006.

12. Moreau-Fauvarque C, Kumanogoh A, Camand E, Jaillard C, Barbin G, Boquet I, Love C, Jones EY, Kikutani H, Lubetzki C, Dusart I and Chédotal A: The transmembrane semaphorin Sema4D/CD100, an inhibitor of axonal growth, is expressed on oligodendrocytes and upregulated after CNS lesion. J Neurosci 23: 9229-9239, 2003.

13. Löw K, Culbertson M, Bradke F, Tessier-Lavigne $M$ and Tuszynski MH: Netrin-1 is a novel myelin-associated inhibitor to axon growth. J Neurosci 28: 1099-1108, 2008.

14. Irizarry-Ramírez M, Willson CA, Cruz-Orengo L, Figueroa J, et al:Upregulation of EphA3 receptor after spinal cord injury. J Neurotrauma 22: 929-935, 2005.

15. Klein R: Bidirectional modulation of synaptic functions by Eph/ ephrin signaling. Nat Neurosci 12: 15-20, 2009.

16. Aoto J and Chen L: Bidirectional ephrin/Eph signaling in synaptic functions. Brain Res 1184: 72-80, 2007.

17. Kullander K, Croll SD, Zimmer M, Pan L, McClain J, Hughes V, Zabski S, DeChiara TM, Klein R, Yancopoulos GD and Gale W: Ephrin-B3 is the midline barrier that prevents corticospinal tract axons from recrossing, allowing for unilateral motor control. Genes Dev 15: 877-888.

18. Asante CO, Chu A, Fisher M, Benson L, Beg A, Scheiffele P and Martin J: Cortical control of adaptive locomotion in wild-type mice and mutant mice lacking the ephrin-Eph effector protein alpha2-chimaerin. J Neurophysiol 104: 3189-3202, 2010.
19. Liu X, Hawkes E, Ishimaru T, Tran T and Sretavan DW: EphB3: an endogenous mediator of adult axonal plasticity and regrowth after CNS injury. J Neurosci 26:3087-3101, 2006.

20. Leighton PA, Mitchell KJ, Goodrich LV, Lu X, Pinson K, Scherz P, Skarnes WC and Tessier-Lavigne M: Defining brain wiring patterns and mechanisms through gene trapping in mice. Nature 410: 174-179, 2001.

21. Yokoyama N, Romero MI, Cowan CA, Galvan P, Helmbacher F, Charnay P, Parada LF and Henkemeyer M: Forward signaling mediated by ephrin-B3 prevents contralateral corticospinal axons from recrossing the spinal cord midline. Neuron 29: 85-97, 2001.

22. Duffy P, Wang X, Siegel CS, Tu N, Henkemeyer M, Cafferty WB and Strittmatter SM: Myelin-derived ephrinB3 restricts axonal regeneration and recovery after adult CNS injury. Proc Natl Acad Sci USA 109: 5063-5068, 2012.

23. Elbashir SM, Harborth J, Weber K and Tuschl T: Analysis of gene function in somatic mammalian cells using small interfering RNAs. Methods 26: 199-213, 2002.

24. Coleman JE, Huentelman MJ, Kasparov S, Metcalfe BL, et al: Efficient large-scale production and concentration of HIV-1-based lentiviral vectors for use in vivo. Physiol Genomics 12: 221-228, 2002.

25. Déglon N, Tseng JL, Bensadoun JC, Zurn AD, Arsenijevic Y, Pereira de Almeida L, Zufferey R, Trono D and Aebischer P: Self-inactivating lentiviral vectors with enhanced transgene expression as potential gene transfer system in Parkinson's disease. Hum Gene Ther 11: 179-190, 2000.

26. Basso DM, Beattie MS and Bresnahan JC:A sensitive and reliable locomotor rating scale for open field testing in rats. J Neurotrauma 12: 1-21, 1995.

27. Goldstein LB: Effects of bilateral and unilateral locus coeruleus lesions on beam-walking recovery after subsequent unilateral sensorimotor cortex suction-ablation in the rat. Restor Neurol Neurosci 11: 55-63, 1997.

28. Silver J and Miller JH: Regeneration beyond the glial scar. Nat Rev Neurosci 5: 146-156, 2004.

29. Genander M and Frisén J: Ephrins and Eph receptors in stem cells and cancer. Curr Opin Cell Biol 22: 611-666, 2010.

30. Carmona MA, Murai KK, Wang L, Roberts AJ and Pasquale EB: Glial ephrin-A3 regulates mhippocampal dendritic spine morphology and glutamate transport. Proc Natl Acad Sci USA 106: 12524-12529, 2009.

31. Goldshmit Y, Galea MP, Wise G, Bartlett PF and Turnley AM: Axonal regeneration and lack of astrocytic gliosis in EphA4-deficient mice. J Neurosci 24: 10064-10073, 2004

32. Benson MD, Romero MI, Lush ME, Lu QR, Henkemeyer M and Parada LF: Ephrin-B3 is a myelin-based inhibitor of neurite outgrowth. Proc Natl Acad Sci USA 102: 10694-10699, 2005.

33. Dorn G, Patel S, Wotherspoon G, et al: siRNA relieves chronic neuropathic pain. Nucleic Acids Res 32: e49, 2002.

34. Xia H, Mao Q, Eliason S, Harper SQ, Martins IH, Orr HT, Paulson HL, Yang L, Kotin RM and Davidson BL: RNAi suppresses polyglutamine-induced neurodegeneration in a model of spinocerebellar ataxia. Nat Med 10: 816-820, 2004.

35. Harper SQ, Staber PD, He X, Eliason SL, Martins IH, Mao Q, Yang L, Kotin RM, Paulson HL and Davidson BL: RNA interference improves motor and neuropathological abnormalities in a Huntington's disease mouse model. Proc Natl Acad Sci USA 102: 5820-5825, 2005.

36. Ralph GS, Radcliffe PA, Day DM, Carthy JM, Leroux MA, Lee DC, Wong LF, Bilsland LG, Greensmith L, Kingsman SM, Mitrophanous KA, Mazarakis ND and Azzouz M: Silencing mutant SOD1 using RNAi protects against neurodegeneration and extends survival in an ALS model. Nat Med 11:429-433, 2005.

37. Raoul C, Abbas-Terki T, Bensadoun JC, Guillot S, Haase G, Szulc J, Henderson CE and Aebischer P: Lentiviral-mediated silencing of SOD1 through RNA interference retards disease onset and progression in a mouse model of ALS. Nat Med 11: 423-428, 2005.

38. Adriaansen J, Vervoordeldonk MJ and Tak PP: Gene therapy as a therapeutic approach for the treatment of rheumatoid arthritis: innovative vectors and therapeutic genes. Rheumatology (Oxford) 45: 656-668, 2006.

39. Manjunath N, Wu H, Subramanya S and Shankar P: Lentiviral delivery of short hairpin RNAs. Adv Drug Deliv Rev 61: 732-745, 2009. 